\title{
KLASIFIKASI ALZHEIMER DAN NON ALZHEIMER MENGGUNAKAN FUZZY C-MEAN, GRAY LEVEL CO- OCCURRENCE MATRIX DAN SUPPORT VECTOR MACHINE
}

\author{
Dian C. R. Novitasari ${ }^{1}$, Wahyu T. Puspitasari ${ }^{2}$, Putri Wulandari ${ }^{3}$, A. Z. Foeady ${ }^{4}$, M. \\ Fahrur Rozi ${ }^{5}$ \\ Universitas Islam Negeri Sunan Ampel Surabaya ${ }^{1,2,3,4,5}$, diancrini @uinsby.ac.id ${ }^{1}$
}

DOI:https://doi.org/10.15642/mantik.2018.4.1.83-89

\begin{abstract}
Abstrak
Berdasarkan Piagam Alzheimer, dua sampai tiga juta kasus demensia oleh penyakit Alzheimer terjadi setiap tahun. Penderita penyakit Alzheimer mengalami gangguan memori dan kognitif secara progresif selama 3 sampai 9 tahun. Penderita mengalami kebingungan dalam memahami pertanyaan serta memiliki urutan memori yang kacau, sehingga dapat mengganggu aktivitas sehari-hari dan apabila dibiarkan akan menyebabkan kematian. Klasifikasi yang dilalukan berdasarkan data Magnetic Resonance Imaging (MRI) penyakit alzheimer dan non alzheimer menggunakan Support Vector Machine (SVM). Segmentasi fitur data menggunakan Fuzzy C-Means (FCM) dan Ekstraksi fitur menggunakan Gray Level Co-Occurrence Matrix (GLCM) memperoleh hasil akurasi yang baik sebesar $93,33 \%$
\end{abstract}

Kata kunci: Alzheimer, Fuzzy C-Means, Gray Level Co-occurence Matrix, Support Vector Machine

\begin{abstract}
Based on the Alzheimer's Charter, 2-3 million cases of dementia by Alzheimer's disease occur every year. People with Alzheimer's disease experience memory and cognitive disorders progressively for 3 to 9 years. Patients experience confusion in understanding the question and have a chaotic sequence of memory, which can interfere with daily activities and unchecked well, it cause death. The classification system is based on Alzheimer's and non-Alzheimer's disease Magnetic Resonance Imaging (MRI) using Support Vector Machine (SVM). The feature data segmentation using Fuzzy C-Means (FCM) and feature extraction using Gray Level Co-Occurrence Matrix (GLCM) and give accuracy result of $93.33 \%$.
\end{abstract}

Keywords: Alzheimer, Fuzzy C-Means, Gray Level Co-occurence Matrix, Support Vector Machine

\section{Pendahuluan}

Seseorang yang telah memasuki usia lanjut seringkali mengalami gangguan ingatan. Gangguan ingatan pada usia lanjut disebabkan kerena syaraf pusat mengalami degenerasi pada syaraf pusat. Gangguan ingatan yang terjadi disebut demensia atau Alzheimer. Sebagian besar penderita Alzheimer mengalami gangguan memori, perubahan kepribadian, suasana hati dan perilaku, bermasalah dalam interaksi [1]. Seseorang yang terkena Alzheimer akan mengalami gangguan secara bertahap. Rata rata gangguan penurunan akan dialami selama tiga sampai sembilan tahun [2].
Teknologi yang semakin maju memungkinkan untuk melakukan deteksi penyakit Alzheimer dapat dilakukan dengan mengambil gambar melalui proses Magnetic resonance imaging (MRI). Hasil dari proses MRI menghasilkan gambar yang dapat dilihat untuk deteksi beberapa penyakit. Menggunakan gambar MRI deteksi penyakit Alzheimer dapat dilakukan dengan melakukan perhitungan numerik. Perhitungan numerik dilakukan dengan mengambil nilai piksel pada gambar MRI pasien. Penggunaan gambar MRI sering dilakukan untuk proses pemeriksaan berbagai macam penyakit pada tubuh. Pada penelitian sebelumnya gambar MRI juga digunakan 


\section{JURNAL MATEMATIKA "MANTIK" \\ Oktober 2018. Vol. 04 No. 02}

ISSN: 2527-3159

E-ISSN: 2527-3167

untuk melakukan deteksi kanker prostat [3]. Selain itu penelitian yang lain citra MRI digunakan juga untuk melihat kandungan lemak pada sumsum tulang belakang [4]. Dari beberapa penelitian tersebut menghasilkan hasil yang maksimal dengan menggunakan citra MRI sebagai citra masukan yang dapat digunakan sebagai acuan.

Menggunakan hasil MRI, deteksi Alzheimer dapat dilakukan dengan melakukan segmentasi pada gambar. Segementasi dilakukan untuk membantu pengambilan fitur fitur yang diinginkan dan membuang background yang dapat mengganggu proses klasifikasi penyakit Alzheimer. Pada penelitian sebelumnya segmentasi optik disk dilakukan dengan menggunakan metode Fuzzy C-Means [5]. Selain itu pada penelitian sebelumnya, metode Fuzzy C-Means juga digunakan untuk segmentasi gambar MRI [6]. Menggunakan algoritma Fuzzy C-Means gambar MRI akan memisahkan antara fitur yang diperlukan ataupun fitur yang tidak diperlukan untuk proses selanjutnya. Fuzzy $C$-Means juga dapat digunakan untuk melakukan segmentasi pada citra mammogram untuk melakukan deteksi kanker payudara [7]. Penelitian sebelumnya menyatakan Fuzzy C-Means dapat dapat digunakan secara optimal untuk melakukan segmentasi pada sebuah citra [8]. Melalui algoritma Fuzzy C-Means gambar MRI akan memisahkan antara fitur yang diperlukan ataupun fitur yang tidak diperlukan untuk proses selanjutnya.

Pengambilan fitur Alzheimer dapat diambil dengan melakukan ekstraksi fitur. Hasil dari proses segmentasi Fuzzy C-Means dapat dilakukan ekstraksi fitur menggunakan metode Gray Level Co-Occurrence Matrix (GLCM). Pada penelitian sebelumnya GLCM digunakan untuk pengenalan karakteristik suatu partikel [9]. Selain itu pada penelitian sebelumnya, GLCM digunakan untuk ekstraksi fitur pada gambar yang memiliki motif berbeda beda [10]. GLCM juga digunakan pada analisis tekstur pada kulit [11]. Pada penelitian yang sudah dilakukan, menyatakan GLCM merupakan salah satu metode yang dapat digunakan untuk melakukan ekstraksi fitur pada suatu data [12]. Gray Level Co-Occurrence Matrix digunakan untuk pengambilan fitur yang dapat digunakan sebagai acuan dalam proses klasifikasi.

Nilai fitur yang dihasilkan pada proses GLCM dapat digunakan untuk klasifikasi pada gambar yang diuji. Pada penelitian sebelumnya klasifikasi dilakukan menggunakan Support Vector Machine (SVM) sebagai metode untuk melakukan entifikasi jenis kanker [13]. Klasifikasi menggunakan Support Vector Machine (SVM) juga digunakan untuk melakukan klasifikasi pada kanker payudara [14]. Dari beberapa penelitian yang sudah dilakukan, klasifikasi dari gambar penyakit otak dapat menggunakan Support Vector Machine (SVM).

Melihat dari beberapa penelitian yang sudah dilakukan dan permasalahan yang ada, penelitian ini bertujuan untuk melakukan klasifikasi gambar MRI penderita Alzheimer dan gambar MRI yang bukan penderita Alzheimer. Untuk segmentasi gambar dilakukan dengan menggunakan Fuzzy $C$ Means dan ekstraksi fitur menggunakan Gray Level Co-Occurrence Matrix, sedangkan klasifikasi dilakukan dengan menggunakan metode SVM.

\section{Tinjauan Pustaka}

\subsection{Fuzzy C-Means Segmentation}

Fuzzy C-Means merupakan salah satu metode yang dapat digunakan untuk melakukan clustering atau pengelompokan suatu data. Penggunaan clustering yang dimiliki oleh Fuzzy $C$-Means dapat juga digunakan untuk pengelompokan nilai piksel pada citra atau serig disebut segmentasi citra. segmentasi menggunakan Fuzzy C-Means dilakukan dengan menghitung nilai keanggotaan pada setiap pikselnya. Metode ini akan digunakan jiga pada suatu bagian citra memiliki dua atau lebih kelompok atau kelas. Data piksel pada citra akan diubah menjadi beberapa kelas yang memiliki derajat keanggotaan yang berbeda beda. Nilai keanggotan mempunyai rentang antara nol sampai satu [15]. Beberapa langkah yang digunakan untuk segmentasi menggunakan Fuzzy C-Means yaitu: 
1. Menyiapkan data yang akan dikelaskan dengan membentuk suatu matriks yang mempunyai ukuran $M x N$, dengan $\mathrm{M}$ sebagai banyak data dan $\mathrm{N}$ merupakan banyak variabel yang digunakan.

2. Menentukan nilai eror (e), banyak kelas (C), bobot (w), awal iterasi dan banyaknya iterasi $(\mathrm{t})$, dan fungsi objektif awal (p).

3. Membuat bilangan acak sebagai awal elemen matriks partisi dengan ukuran $M x C$.

4. Menghitung pusat kelompok menggunakan persamaan 1 sebagai berikut.

$$
v_{k j}=\frac{\sum_{i=1}^{m} \mu_{i k}{ }^{w} x_{i j}}{\sum_{i=1}^{m} \mu_{i k}{ }^{w}}
$$

Dengan :

$v_{k j}=$ pusat cluster ke k untuk atribut ke j

$\mu_{i k}=$ derajat keanggotaan untuk data sampel ke i pasa cluster ke $\mathrm{k}$ $x_{i j}=$ datake $i$, atribut ke $j$

5. Menghitung fungsi objektif pada iterasi ke $\mathrm{t}$ dengan persamaan 2 sebagai berikut.

$$
P_{t}=\sum_{i=1}^{m} \sum_{k=1}^{c}\left(\left[\sum_{j=1}^{n}\left(x_{i j}-v_{k j}\right)^{2}\right]\left(\mu_{i k}\right)^{w}\right)
$$

6. Menghitung perubahan matriks partisi

$$
\mu_{i k}=\frac{\left[\sum_{j=1}^{c}\left(x_{i j}-v_{k j}\right)^{2}\right]^{\frac{1}{w-1}}}{\sum_{k=1}^{c}\left[\sum_{j=1}^{c}\left(x_{i j}-v_{k j}\right)^{2}\right]^{\frac{1}{w-1}}}
$$

\subsection{Gray Level Co-occurrence Matrix}

Gray Level Co-Occurrence Matrix (GLCM) merupakan salah satu metode ekstraksi fitur yang menggunakan histogram orde kedua dari tingkat keabuan [16]. Pengambilan fitur didasarkan pada dua parameter, yaitu jarak dan sudut, dimana jarak adalah selisih piksel yang digunakan untuk the second order statistics, dan sudut yang terbentuk antara pasangan piksel. Dalam metode GLCM, orientasi sudut dinyatakan dalam derajat. Orientasi sudut dibagi menjadi 4 arah sudut yang berbeda dengan interval $45^{\circ}$, yaitu $0^{\circ}, 45^{\circ}, 90^{\circ}$, $135^{\circ}$ [17]. Misalkan $\mathrm{f}(\mathrm{a}, \mathrm{b})$ adalah citra dengan ukuran $\mathrm{Na}$ dan $\mathrm{Nb}$ yang memiliki piksel dengan kemungkinan $\mathrm{L}$ level dan $\mathrm{p}$ adalah vektor arah offset spasial. GLCM (i,j) didefinisikan sebagai jumlah piksel (j) yang terjadi pada offset $r$ terhadap piksel (i) yang dapat dinyatakan ssebagai berikut

$$
\operatorname{GLCM}(i, j)=\left\{\left(x_{-} 1, y_{\_} 1\right),\left(x_{-} 2, y_{\_} 2\right)\right\}
$$

dimana offset $r$ dapat berupa sudut atau jarak, $\mathrm{j} \in 1, \ldots, \mathrm{L}$, dan $\mathrm{i} \in 1, \ldots$,L. Matriks co occurrence digunakan untuk mendapatkan fitur dari citra. Beberapa besaran yang diusulkan Harlick untuk mendapatkan fitur dari GLCM yaitu Angular Second Moment (ASM), kontras, Inverse Difference Moment (IDM), energi, korelasi [18].

\subsubsection{Angular Second Moment (ASM)}

ASM juga dikenal sebagai keseragaman. ASM berhubungan dengan energi, dimana energi merupakan jumlah kuadrat elemenelemen GLCM angular second moment untuk mengukur homogenitas. Nilai tertinggi dicapai ketika gambar memiliki homogenitas yang sangat baik yaitu saat elemen GLCM semuanya sama [19]. ASM dihitung dengan menggunakan rumus pada persamaan 6 berikut.

$$
A S M=\sum_{i} \sum_{j}(G \operatorname{LCM}(i, j))^{2}
$$

\subsubsection{Kontras}

Kontras merupakan ukuran variasi aras keabuan piksel citra. Kontras dihitung dengan menggunakan persamaan 6 sebagai berikut.

$$
\text { Contras }=\sum_{i} \sum_{j}(i-j)^{2} \operatorname{GLCM}(i, j)
$$

\subsubsection{Invers Difference Moment (IDM)}

IDM memiliki nilai tinggi saat tingkat keabuan lokal sama dan balikan GLCM tinggi. IDM dihitung dengan menggunakan persamaan 7 sebagi berikut.

$$
I D M=\sum_{i} \sum_{j} \frac{\operatorname{GLCM}(i, j)}{1+(i, j)^{2}}
$$

\subsubsection{Entropy}


Entropy merupakan pengukuran keacakan aras keabuan di dalam citra. Mencapai nilai tertinggi ketika elemen-elemen GLCM memiliki nilai yang relatif sama dan memiliki nilai rendah apabila elemen-elemen GLCM mendekati 0 atau 1. Entropi dihitung dengan menggunakan rumus [20].

Entropy $=-\sum_{i} \sum_{j} \operatorname{GLCM}(i, j) \log G L C M$

\subsubsection{Korelasi}

Korelasi digunakan menghitung ketergantungan linear tingkat keabuan dari piksel tetangga. Untuk mendapatkan nilai korelasi dapat menggunakan rumus berikut :

$$
\text { Corelation }=\frac{\sum_{i} \sum_{j}(i j) \operatorname{GLCM}(i, j)-\mu_{i}^{\prime} \mu_{j}}{\sigma_{i}^{\prime} \sigma_{j}^{\prime}}
$$

\subsection{Support Vector Machine (SVM)}

Support Vector Machine merupakan salah satu metode yang digunakan untuk melakukan klasifikasi suatu data. Support Vector Machine akan melakuka klasifikasi data dengan membagi data menjadi beberapa daerah sesuai denga banyaknya klasifikasi yang diinginkan. Untuk melakukan pembagian data, metode Support Vector Machine menggunakan hyperplane sebagai garis bagi sebagai garis pemisah antara kelompok pada kelas satu dengan kelas yang lain. Pembuatan garis bagi atau hyperplane dapat dibentuk menggunakan beberapa fungsi kernel yang ada pada metode Support Vector Machine. Beberapa fungsi kernel yang dapat digunakan untuk membangkitkan suatu hyperplane yaitu kernel gaussian, linear, ataupun polynomial [21].

Pada penelitian ini fungsi kernel yang digunakan menggunakan fungsi polinomial. Pemilihan fungsi polinomial karena pada penelitian ini hasil Support Vector Machine menunjukkan hasil yang optimal menggunakan fungsi kernel polinomal. Adapun fungsi kernel polinomial dibentuk menggunakan persamaan 10 .

$$
K(x, y)=(x \cdot y)^{d}
$$

\section{Penulisan Tabel dan Gambar}

\subsection{Jenis Penelitian}

Pada penelitian mengenai identifikasi penyakit Alzhaimer menggunakan metode GLCM dan SVM termasuk kedalam jenis penelitian aplikatif karena data input dan output yang digunakan dalam penelitian ini berupa data numerik, dan hasil dari penelitian ini betujuan sebagai alternatif diagnosa penyakit Alzheimer.

\subsection{Pengumpulan Data}

Data yang digunakan dalam penelitian ini merupakan data axial otak MRI yang akan digunakan untuk mendapatkan karakteristiknya dengan menggunakan metode DWT. Terdapat 95 data citra axial otak MRI. Data tersebut diperoleh dari Alzheimer's Disease Neuroimageing Initiative (ADNI) dan E-Health Laboratory.

\subsection{Pengolahan Data}

Tahap-tahap yang dilakukan dalam identifikasi penyakit Alzheimer yaitu, preprocessing, segmentasi fitur, ekstraksi fitur, dan pengklasifikasian. Pada penelitian ini, data akan diklasifikasikan menjadi dua jenis yaitu Alzheimer dan non-Alzheimer.

Tahap pertama, dilakukan preprocessing yang befungsi untuk mempermudah proses dalam pengolahan citra, karena tidak semua data citra memiliki kualitas yang baik sehingga kontras dan pencahayaan terkadang tidak merata. Selain itu, terdapat noise yang berbeda dari masing-masing data citra. Pada tahap pre-processing, data otak MRI merupakan citra grayscale. Selanjutnya dilakukan peningkatan cahaya dengan mengubah histogram yang bertujuan untuk menormalisasi citra.

Citra yang telah diproses akan digunakan sebagai masukan dalam segmentasi fitur menggunakan Fuzzy C-Mean (FCM). Jumlah cluster yang dimasukan sebanyak tiga sehingga diperoleh tiga fitur yaitu gray matter (GM), white matter (WM), dan cerebrospinal fluid (CSF). Dari tiga fitur tersebut, fitur yang diambil hanya fitur GM.

Tahap ketiga adalah ekstraksi fitur. Dalam penelitian ini, ekstraksi fitur dengan metode GLCM menggunakan derajat ketetanggan $0^{\circ}$. Dari setiap sub-band diambil 
Oktober 2018. Vol. 04 No. 02

ISSN: 2527-3159

E-ISSN: 2527-3167

beberapa fitur yaitu kontras, korelasi, energi, dan homogenitas. Fitur tersebut akan digunakan dalam tahapan klasifikasi.

Dalam proses klasifikasi terdapat beberapa step yaitu menentukan parameter ciri, memilih kernel mana yang cocok dengan data. Melakukan pelatihan dan melakukan pengujian data hingga mendapatkan hasil klasifikasi. Dalam penelitian ini menggunakan kernel polinomial. Skema tahap-tahap identifikasi Alzheimer ditunjukan dalam Gambar. 1.

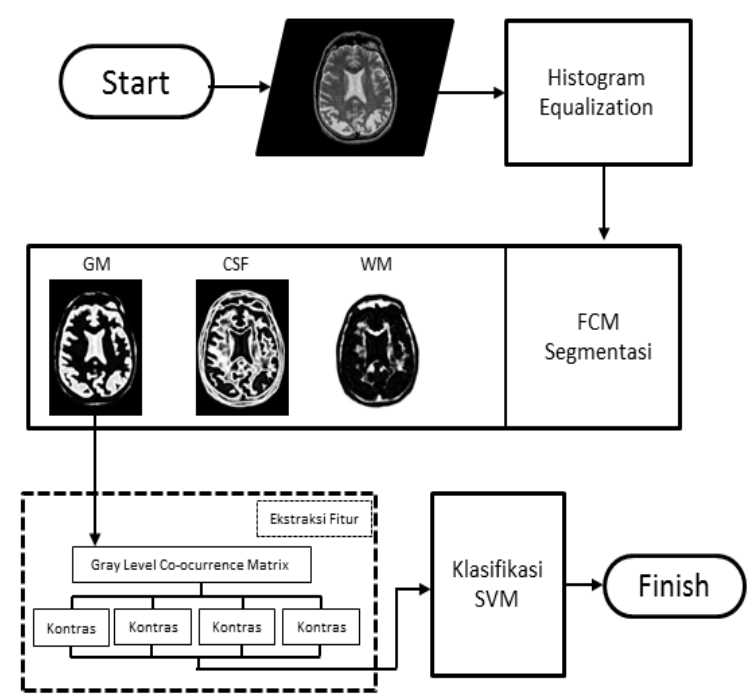

Gambar 1 Flowchat identifikasi Alzheimer

\section{Hasil dan Pembahasan}

Untuk mengidentifikasi penyakit Alzheimer dilakukan menggunakan metode FCM, GLCM dan SVM dengan fungsi secara berurutan untuk segmentasi, ekstrasi fitur, dan klasifikasi. Sebelum dilakukan segmentasi diperlukan preprocessing citra yang bertujuan untuk memperbaiki kualtitas citra. Pada tahap preprocessing, citra diperbaiki menggunakan histogram equalization. Proses Histogram equalization digunakan untuk memperoleh penyebaran histogram derajat keabuan citra yang merata dan relatif sama. Hasil histogram equalization tersebut akan disegmentasi fitur berupa Gray Matter (GM), White Matter (WM) dab Cerebrospinal fluid (CSF). Fitur yang diambil untuk proses ekstraksi fitur hanya GM. Pada Gambar 3 ditunjukkan Citra hasil preprocessing dan segmentasi fitur.
Setelah didapatkan hasil segmentasi kemudian dilakukan proses ekstraksi fitur menggunakan metode GLCM. Proses ekstraksi fitur dilakukan untuk mendapatan ciri statistik pada citra. Pada penelitian ini menggunakan GLCM dengan derajat ketetanggan $0^{\circ}$ diambil ciri statistik yang berupa kontras, korelasi, energi, homogenitas. Sampel hasil ekstraksi fitur menggunakan GLCM ditampilkan pada Tabel 1.

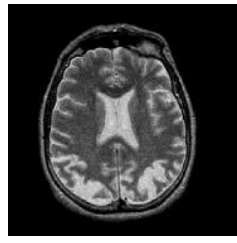

(a)

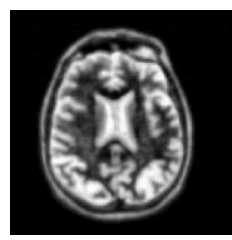

(b)

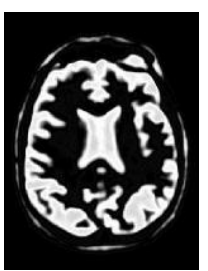

(c)

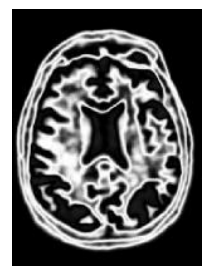

(d)

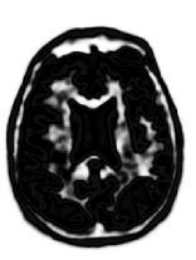

(e)
Gambar 3 (a) Barin MRI (b) Histogram Equalization (c) Gray Matter (d) Cererospinl Fluid (e) White Matter

Selanjutnya akan dilakukan klasifikasi menggunakan SVM. Fitur-fitur yang telah diperoleh pada proses ekstraksi fitur akan digunakan sebagai parameter dalam klasifikasi. Pada proses klasifikasi dilakukan melalui dua tahap yaitu tahap training dan tahap testing. Tahap training merupakan tahap pembuatan model, sedangkan tahap tesing merupakan tahap pengujian keakuratan model. Data training yang digunakan sebanyak 50 data dan data uji yang digunakan sebanyak 45 data yang kemudian akan diklasifikasi kedalam dua kelas yaitu Alzheimer dan non-Alzheimer. Proses klasifikasi dilakukan dengan menggunakan kernel polinomial.

Tabel 1. Sampel Hasil ekstraksi fitur menggunakan GLCM.

\begin{tabular}{|c|c|c|c|c|}
\hline $\begin{array}{c}\text { Data } \\
\text { ke- }\end{array}$ & Kontras & Korelasi & Energi & $\begin{array}{c}\text { Homogen } \\
\text { iti }\end{array}$ \\
\hline 1 & 0,608802 & 0,929677 & 0,700024 & 0,944456 \\
\hline 2 & 0,830997 & 0,915252 & 0,662213 & 0,938277 \\
\hline 3 & 0,682498 & 0,916594 & 0,720156 & 0,947706 \\
\hline
\end{tabular}




\begin{tabular}{|c|r|r|r|r|}
\hline 4 & 0,660632 & 0,924824 & 0,705951 & 0,947408 \\
\hline 5 & 0,710567 & 0,925752 & 0,686143 & 0,945724 \\
\hline 6 & 0,733653 & 0,921226 & 0,690052 & 0,946255 \\
\hline 7 & 0,757863 & 0,926632 & 0,662385 & 0,942731 \\
\hline 8 & 0,788584 & 0,930982 & 0,636891 & 0,940234 \\
\hline 9 & 0,802268 & 0,921175 & 0,626319 & 0,935237 \\
\hline 10 & 0,815404 & 0,92574 & 0,629073 & 0,936168 \\
\hline
\end{tabular}

Dari hasil klasifikasi tersebut, terdapat 45 data testing, 14 data benar terklasifikasi nonAlzheimer dan 28 data benar terklasifikasi Alzheimer sehingga diperoleh akurasi sebesar 93,333\% dengan tingkat sensitivitas 93,333\% dan spesifisitas 93,333\%. Dari hasil tersebut menunjukkan bahwa metode ini mampu mengenali masing-masing kelas dengan sangat baik. Sehingga metode ini cocok digunakan untuk mengidentifikasi Alzheimer.

\section{Kesimpulan}

Berdasarkan percobaan yang telah dilakukan, identifikasi penyakit Alzheimer menggunakan Fuzzy C-Means untuk segmentasi fitur, Gray Level Co-Occurrence Matrix untuk proses ekstraksi fitur sedangkan untuk klasifikasi menggunakan Support Vector Machine diperoleh hasil terbaik dengan nilai akurasi sebesar 93,33\%. Berdasarkan hasil yang telah diperoleh, dapat disimpulkan bahwa metode tersebut sangat cocok digunakan untuk indentifikasi penyakit Alzheimer dengan tingkat sensitifitas $93.33 \%$ dan spesifitas $93.33 \%$.

\section{Referensi}

[1] N. Gharaibeh and A. A. Kheshman, "Automated Detection of Alzheimer Disease Using Region Growing technique and Artificial Neural Network," vol. 7, no. 5, pp. 204-208, 2013.

[2] D. Zhang, Y. Wang, L. Zhou, H. Yuan, and D. Shen, "Multimodal classification of Alzheimer's disease and mild cognitive impairment," Neuroimage, vol. 55, no. 3, pp. 856-867, 2011.

[3] M. R. Pokorny et al., "Prospective study of diagnostic accuracy comparing prostate cancer detection by transrectal ultrasoundguided biopsy versus magnetic resonance (MR) imaging with subsequent mr-guided biopsy in men without previous prostate

biopsies," Eur. Urol., vol. 66, no. 1, pp. 22-29, 2014.

[4] E. Michael and S. Vinitski, "BONE MARROW FINDINGS ON MAGNETIC RESONANCE IMAGES OF THE KNEE : ACCENTUATION BY FAT SUPPRESSION," vol. 8, pp. 27-31, 1990.

[5] N. Elaiza, A. Khalid, N. Mohamed, and N. Ariff, "Fuzzy C-Means ( FCM ) for Optic Cup and Disc Segmentation with Morphological Operation," Procedia Procedia Comput. Sci., vol. 42, pp. 255262, 2014.

[6] S. Kumar, J. Kanta, D. Kumar, and M. Nasipuri, "Conditional spatial Fuzzy CMeans clustering algorithm for segmentation of MRI images," Appl. Soft Comput. J., vol. 34, pp. 758-769, 2015.

[7] S. R. Kannan, S. Ramathilagam, R. Devi, and A. Sathya, "Expert Systems with Applications Robust kernel FCM in segmentation of breast medical images," Expert Syst. Appl., vol. 38, no. 4, pp. 4382-4389, 2011.

[8] X. Wang and J. Bu, "A fast and robust image segmentation using FCM with spatial," Digit. Signal Process., vol. 20, no. 4, pp. 1173-1182, 2010.

[9] K. Manivannan, P. Aggarwal, V. Devabhaktuni, A. Kumar, D. Nims, and P. Bhattacharya, "Particulate matter characterization by Gray Level CoOccurrence Matrix based support vector machines," J. Hazard. Mater., vol. 223224, pp. 94-103, 2012.

[10] G. Y. Peng Yang, "Author' s Accepted Manuscript Reference: To appear in: Neurocomputing," Neurocomputing, 2016.

[11] P. M. Arabi, G. Joshi, and N. V. Deepa, "Performance evaluation of GLCM and pixel intensity matrix for skin texture analysis," Perspect. Sci., 2016.

[12] Ş. Öztürk and B. Akdemir, "Application of Feature Extraction and Classification Methods for Histopathological Image using GLCM, LBP, LBGLCM, GLRLM and SFTA," Procedia Comput. Sci., vol. 132, no. Iccids, pp. 40-46, 2018.

[13] S. P. Wang and Y. D. Cai, "Identification of the functional alteration signatures across different cancer types with Support 
Vector Machine and feature analysis," Biochim. Biophys. Acta - Mol. Basis Dis., vol. 1864, no. 6, pp. 2218-2227, 2018.

[14] C. S. Lo and C. M. Wang, "Support Vector Machine for breast MR image classification," Comput. Math. with Appl., vol. 64, no. 5, pp. 1153-1162, 2012.

[15] M. C. J. Christ, "Fuzzy C-Means Algorithm for Medical Image Segmentation," no. 1, pp. 33-36, 2011.

[16] S. E. Embough, Digital Image Processing and Analysis Aplicaton with MATLAB and CVIP Third Edition. Boca Raton: CRC Press, 2017.

[17] Y. Q. Shi and B. Jeon, Digital Watermarking. Korea: Springer, 2006.

[18] A. Kadir, Teori dan Aplikasi Pengolahan Citra. Yogyakarta: Andi, 2013.

[19] P. Mohanaiah, P. Sathyanarayana, and L. GuruKumar, "image Texture Fearure Etraction Using GLCM Approach," IJSRP, vol. 3, no. 5, 2013.

[20] N. Zulpe and V. Pawar, "GLCM Texture Features for Brain Tumor Classification," IJCSI, vol. 9 No. 3. 1, 2012.

[21] Jiawei Han and Micheline Kamber, Data Mining, Second. San Francisco: Morgan Kaufmann Publisher, 2006. 